\title{
A Study on Identification of Consumer Groups Buying at Apparel Retail Store: A Cluster Analysis
}

\author{
Manikandan M K M
}

\section{Abstract}

The Indian Retail Industry is growing at such a fast rate that many foreign retailers want to capitalize on the growth momentum and the opportunity offered by the growing buying power of middle class. Many retailers are already present in Indian retail landscape and they are finding it difficult to run the business profitably. Not many India specific retail research has been carried out so far. Of late many researchers are coming up with studies that focus on India specific retailing. This study tries to study the type of customers who are visiting the apparel retailers and tries to group them based on certain parameters like their occupation, continued patronage and age. Cluster analysis is used as a statistical tool to group the sample into various groups. The result indicates the existence of four types of customer groups for the apparel retailing stores.

Keywords: Retail, Middle class, India specific retail research, Cluster analysis.

\section{Introduction}

Retailing in India happens through a vast number of unorganized retailers with over 12 million retail outlets spread across the country in various sizes and formats. India has the largest retail density with 9 stores available for every 1000 people. The Indian

\footnotetext{
* Assistant Professor, KPR School of Business, Arasur, Coimbatore 641 407; mkmmanikandan@gmail.com
} 
retail industry provides $8 \%$ of the country's employment with its vast distribution of retail stores across the country. The business model followed by the retailer is generally called as "Format". By way of classification of stores on location, one can classify the store as Chain Store Format, High Street Format, Destination Format, and Convenience Format. Formats like Franchisee Model, Independent Retail stores fall under the category of store format by Ownership.

Modern retailing in India is seen in the form of Malls, complexes that offer entertainment, cinema, and food along with shopping. We can say that shopping today has become part of entertainment. At the same time, local kirana stores continue to score over modern formats due to the convenience they offer to the customers.

One of the benefits of modern retailing format is that it develops a systematic supply chain of goods leading to efficiency in the entire chain that results in savings to all the parties involved. The revenue to the government also increases due to the efficiency of tax collection. The kirana retailing has been one of the easiest ways to generate self-employment, as it requires minimum investment in terms of land, labour and capital. In order to keep pace with the modern formats, kiranas have now started providing more valueadded services like stocking ready- to- cook vegetables and other fresh produce. They also provide services like credit, phone service, home delivery etc.

\section{Rising Incomes}

McKinsey report states that the current share of India's Per-capita Purchasing Power Parity will rise from the current 4.7 to 6.1 percent by the year 20151. Today, with the advancement in technology and infrastructure, the growth in the urban area is transforming the rural population also.

\section{Consumer Satisfaction}

Customer satisfaction denotes meeting the expectations of consumers. Customer satisfaction is a competitive advantage for a company when compared to the competitors. A brand that gains in customer satisfaction creates a positive word of mouth among the public. 
Retaining the existing customers is a wise decision compared to acquiring new customers, as getting new customers is considered a costly activity. (Reichheld, 1996; Stone et al., 1996). Dekimpe et al (1997) state that loyal customers are considered to be the assets for a company. Companies should involve in activities that create loyalty of the customers. Loyalty is attained from customer satisfaction.

Oliver (1999) proves that customer satisfaction is the reason for customers' change in perception over a product. It is because of this evaluative reasoning, that customers are changing their attitude towards certain products after consumption (Day, 1984). Satisfaction is defined as the customer's evaluation of the product before the purchase and seeing the performance after the purchase is done (Beardon and Teel; 1983). If there is a match between the pre purchase and post purchase evaluation, the customer is satisfied and if not, there will be dissatisfaction. Lowenstein (1995) states that customer satisfaction is an important factor in the customer remaining loyal to the store or the product. Expectation is the key factor in the studies involving customer satisfaction. When a customer attaches high expectation from a product, a good performing brand may be felt as unsatisfactory and with low expectation on the product, a customer may develop a positive satisfaction over the product.

\section{Research Methodology}

This research has been carried out in the city of Bangalore, for apparel store. The store that was identified for the study was the apparel brand store 'MegaMart' in Bangalore city. MegaMart is an established brand in the market for branded apparels and it has been existing for quite some time. Data was collected in four different locations where the store was present. Consumers visiting the apparel stores were approached for data collection. Samples were collected through a convenient sampling method.

A structured questionnaire was developed covering the concepts of customer satisfaction and the factors that are given importance while making a buy at the store. Satisfaction was studied by getting the responses of price related question, ambience, reliability of the 
store brand, product availability in the store, satisfaction from customer service. Finally the customers were asked about the overall satisfaction from the stores. The responses were scored through Likert 5 point scale. Demographic factors like age, gender, occupation, were included in the responses. Further, information related to how customers get information about the store, whether obtained through inclusion of responses advertisement, friends or from the retail store sales person. The customers' prior exposure to the store was obtained by asking them whether they had visited the store before, through dichotomous response. A total of 100 samples were collected. The data was further analyzed for cluster analysis to group the customers so that the store can identify the customer group that gives patronage to the store.

\section{Objectives}

1. To group the customers of the store 'MegaMart' based on Customer Satisfaction and demographic variables.

2. To understand the relationship between the occupation of customers and their loyalty to the store.

3. To understand the relationship between the occupation of customers and the overall satisfaction of the customers.

\section{Hypothesis}

H1. There exists a relationship between occupation and loyalty factor of consumers towards the stores.

H2. There exists a relationship between occupation and overall satisfaction of customers towards the stores.

\section{Data Analysis and Interpretation}

The collected data was analysed using SPSS 17 software for the statistical tests of Reliability, Cluster Analysis and Correlation.

The reliability tests yield a test result of Cronbach's Alpha value 0.745 . 
The cronbach's alpha value of 0.7 to 0.8 is acceptable range. Hence the six variables used to study the customer satisfaction holds good.

\section{Grouping of Customers}

As the study intends to get respondents in to various groups, a cluster analysis was performed. Cluster analysis helps the cases or respondents fall in to groups so that they are dissimilar among the clusters but are similar within the clusters. For the present study, the hierarchical clustering method was used to group the respondents into various clusters. The default method that comes with the hierarchical method in SPSS is used for clustering.

Table 2, found below, details the clusters formed in each stage. In stage 1, the cases (respondents) 82 and 95 are combined as first stage. Case 52 and 92 were combined as clusters in stage 2, and so on. The last column details the next stage at which the present cases in the stage combine with other cases. The cases in stage one combine with other cases in state 27 . If we move down to case 27 we can find that case 54 combines with case 82 .

The column Coefficient will be useful in judging the number of clusters that may be possible in the study. The biggest difference in the coefficient value will be taken as one cluster, and considering that, this study yields four big differences. The first big change in coefficient value is between stage $7 \& 8$ with a difference of 1 . The next big difference happens at the stage $88 \& 89$ with a difference of 1.4 , the next difference happens at the stage $95 \& 96$ and $97 \& 98$ with a difference in coefficient value of 1.69 and 2.578 respectively. Hence for this study we get a cluster of 4 groups and that is subjective. More details of the clustering of the cases can be had from the Icicle table (Fig 1) and the Dendrogram, (Table 3) given below.

\section{Cluster 1}

This Cluster is represented by people in the age group of 20 to 30 years and both male and female shoppers are falling under this cluster. The respondents who come under this cluster are both students and employed people, and they like to get informed primarily through the store sales persons and some get informed 
from advertisement. They have already visited the store before for purchase and are buying the goods for the last one year. They are neither satisfied nor dissatisfied with the store services but they are inclined for more purchases.

\section{Cluster 2}

The constituent members of this group are exclusively males and are in the age group of 20 to 40 years. No female customers are seen in this group. All the members who form the clusters are business persons. They are first time buyers and they are neutral to the service from the store and are informed about the store through advertisements and friends.

\section{Cluster 3}

These groups of respondents are in the age group of 20 to 30 years and are predominantly males. Both students and employed professionals fall under this group. They get the store information from friends and advertisements. This group consists of people who are first time buyers and are dissatisfied with the service of the store.

\section{Cluster 4}

This group is represented by housewives and business persons in the age group of 20 to 40 years. They like to get the information from the store sales persons and some get informed through advertisement. They have visited the store before and have been buying the merchandises for more than a year. They are happy with the service offered from the store.

\section{Relationship between Occupation and Loyalty}

In order to find the relationship between the occupation of the respondent and loyalty to the store, correlation test was conducted, and Table 4 shows a significant relationship between variable Occupation and Loyalty and Occupation and Overall Store Loyalty. We reject the null hypothesis and accept the alternate hypothesis. This shows that there is significant association between the occupation of customers and customer loyalty and overall satisfaction of customers. 


\section{Conclusion}

The study done in the apparel store on the group of customers who visit the store, based on the variables, information they seek from, number of visits they made to the store for the last two years and type of customers have been used to do the cluster analysis. The result indicates that there is a clear difference among the business class people and homemakers and students and employed people in terms of satisfaction they get from the store. The group of students and employed are more demanding in terms of service from the store whereas business people and homemakers are satisfied with the existing service they get from the store. Appropriate strategy may be adopted by the retail store operators to satisfy the demand of customers.

\section{Future Scope}

The current study lacks in certain aspects; it has taken only one store for the study and only limited components have been taken up for the cluster study. More components may be considered and the study may be extended to other stores also so that a general segmentation of apparel customers may be defined.

\section{Annexure}

\begin{tabular}{|c|c|}
\hline \multicolumn{2}{|c|}{ Table 1: Reliability Statistics } \\
\hline Cronbach's Alpha & N of Items \\
\hline .745 & 6 \\
\hline
\end{tabular}


Table 2: Agglomeration Schedule

\begin{tabular}{|c|c|c|c|c|c|c|}
\hline Stage & Cluster & Combined & 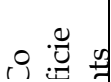 & $\begin{array}{r}\text { Stage Cl } \\
\text { App }\end{array}$ & $\begin{array}{l}\text { ster First } \\
\text { ears }\end{array}$ & Next Stage \\
\hline & Cluster 1 & Cluster 2 & 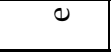 & Cluster 1 & Cluster 2 & \\
\hline 1 & 82 & 95 & 2.000 & 0 & 0 & 27 \\
\hline 2 & 52 & 92 & 2.000 & 0 & 0 & 32 \\
\hline 3 & 8 & 90 & 2.000 & 0 & 0 & 23 \\
\hline 4 & 14 & 80 & 2.000 & 0 & 0 & 32 \\
\hline 5 & 16 & 79 & 2.000 & 0 & 0 & 47 \\
\hline 6 & 21 & 74 & 2.000 & 0 & 0 & 46 \\
\hline 7 & 45 & 53 & 2.000 & 0 & 0 & 85 \\
\hline 8 & 4 & 100 & 3.000 & 0 & 0 & 48 \\
\hline 9 & 73 & 98 & 3.000 & 0 & 0 & 35 \\
\hline 10 & 59 & 93 & 3.000 & 0 & 0 & 22 \\
\hline 11 & 41 & 87 & 3.000 & 0 & 0 & 23 \\
\hline 12 & 31 & 85 & 3.000 & 0 & 0 & 58 \\
\hline 13 & 11 & 84 & 3.000 & 0 & 0 & 44 \\
\hline 14 & 30 & 83 & 3.000 & 0 & 0 & 39 \\
\hline 15 & 76 & 77 & 3.000 & 0 & 0 & 62 \\
\hline 16 & 61 & 75 & 3.000 & 0 & 0 & 36 \\
\hline 17 & 10 & 71 & 3.000 & 0 & 0 & 37 \\
\hline 18 & 43 & 68 & 3.000 & 0 & 0 & 53 \\
\hline 19 & 55 & 65 & 3.000 & 0 & 0 & 51 \\
\hline 20 & 42 & 48 & 3.000 & 0 & 0 & 38 \\
\hline 21 & 7 & 24 & 3.000 & 0 & 0 & 58 \\
\hline 22 & 51 & 59 & 3.500 & 0 & 10 & 40 \\
\hline 23 & 8 & 41 & 3.500 & 3 & 11 & 51 \\
\hline 24 & 63 & 97 & 4.000 & 0 & 0 & 44 \\
\hline 25 & 32 & 91 & 4.000 & 0 & 0 & 41 \\
\hline 26 & 19 & 86 & 4.000 & 0 & 0 & 57 \\
\hline 27 & 54 & 82 & 4.000 & 0 & 1 & 37 \\
\hline 28 & 39 & 81 & 4.000 & 0 & 0 & 56 \\
\hline 29 & 60 & 78 & 4.000 & 0 & 0 & 45 \\
\hline 30 & 12 & 70 & 4.000 & 0 & 0 & 76 \\
\hline
\end{tabular}


A Study on Identification of Consumer Groups Ushus JBMgt 12, 4 (2013)

\begin{tabular}{|l|r|r|r|r|r|r|}
\hline 31 & 26 & 57 & 4.000 & 0 & 0 & 48 \\
\hline \hline 32 & 14 & 52 & 4.000 & 4 & 2 & 50 \\
\hline 33 & 47 & 49 & 4.000 & 0 & 0 & 68 \\
\hline 34 & 9 & 37 & 4.000 & 0 & 0 & 40 \\
\hline 35 & 44 & 73 & 4.500 & 0 & 9 & 53 \\
\hline \hline 36 & 15 & 61 & 4.500 & 0 & 16 & 65 \\
\hline 37 & 10 & 54 & 4.500 & 17 & 27 & 61 \\
\hline \hline 38 & 6 & 42 & 4.500 & 0 & 20 & 49 \\
\hline \hline 39 & 25 & 30 & 4.500 & 0 & 14 & 66 \\
\hline \hline 40 & 9 & 51 & 4.667 & 34 & 22 & 73 \\
\hline \hline 41 & 32 & 94 & 5.000 & 25 & 0 & 69 \\
\hline \hline 42 & 18 & 89 & 5.000 & 0 & 0 & 64 \\
\hline \hline 43 & 38 & 67 & 5.000 & 0 & 0 & 82 \\
\hline \hline 44 & 11 & 63 & 5.000 & 13 & 24 & 52 \\
\hline \hline 45 & 23 & 60 & 5.000 & 0 & 29 & 73 \\
\hline \hline 46 & 21 & 33 & 5.000 & 6 & 0 & 71 \\
\hline 47 & 16 & 27 & 5.000 & 5 & 0 & 71 \\
\hline \hline 48 & 4 & 26 & 5.000 & 8 & 31 & 63 \\
\hline \hline 49 & 6 & 17 & 5.333 & 38 & 0 & 69 \\
\hline \hline 50 & 14 & 34 & 5.500 & 32 & 0 & 63 \\
\hline \hline 51 & 8 & 55 & 5.750 & 23 & 19 & 62 \\
\hline \hline 52 & 11 & 36 & 5.750 & 44 & 0 & 81 \\
\hline \hline 53 & 43 & 44 & 5.833 & 18 & 35 & 72 \\
\hline \hline 54 & 58 & 96 & 6.000 & 0 & 0 & 84 \\
\hline \hline 55 & 40 & 72 & 6.000 & 0 & 0 & 67 \\
\hline \hline 56 & 39 & 62 & 6.000 & 28 & 0 & 68 \\
\hline \hline 57 & 19 & 46 & 6.000 & 26 & 0 & 76 \\
\hline 58 & 7 & 31 & 6.000 & 21 & 12 & 92 \\
\hline \hline 59 & 5 & 29 & 6.000 & 0 & 0 & 78 \\
\hline \hline 60 & 22 & 28 & 6.000 & 0 & 0 & 82 \\
\hline \hline 61 & 10 & 13 & 6.000 & 37 & 0 & 70 \\
\hline \hline 63 & 8 & 76 & 6.333 & 51 & 15 & 72 \\
\hline & 4 & 14 & 6.450 & 48 & 50 & 70 \\
\hline
\end{tabular}




\begin{tabular}{|l|r|r|r|r|r|r|}
\hline 64 & 18 & 64 & 6.500 & 42 & 0 & 86 \\
\hline \hline 65 & 15 & 99 & 6.667 & 36 & 0 & 88 \\
\hline \hline 66 & 25 & 66 & 7.000 & 39 & 0 & 74 \\
\hline \hline 67 & 40 & 56 & 7.000 & 55 & 0 & 84 \\
\hline 68 & 39 & 47 & 7.333 & 56 & 33 & 74 \\
\hline \hline 69 & 6 & 32 & 7.333 & 49 & 41 & 77 \\
\hline \hline 70 & 4 & 10 & 7.444 & 63 & 61 & 79 \\
\hline 71 & 16 & 21 & 7.778 & 47 & 46 & 78 \\
\hline 72 & 8 & 43 & 7.825 & 62 & 53 & 79 \\
\hline \hline 73 & 9 & 23 & 8.067 & 40 & 45 & 83 \\
\hline 74 & 25 & 39 & 8.450 & 66 & 68 & 85 \\
\hline \hline 75 & 20 & 50 & 9.000 & 0 & 0 & 83 \\
\hline \hline 76 & 12 & 19 & 9.000 & 30 & 57 & 86 \\
\hline \hline 77 & 1 & 6 & 9.286 & 0 & 69 & 80 \\
\hline \hline 78 & 5 & 16 & 9.333 & 59 & 71 & 80 \\
\hline 79 & 4 & 8 & 9.554 & 70 & 72 & 81 \\
\hline \hline 80 & 1 & 5 & 9.969 & 77 & 78 & 87 \\
\hline \hline 81 & 4 & 11 & 9.993 & 79 & 52 & 87 \\
\hline \hline 82 & 22 & 38 & 10.000 & 60 & 43 & 90 \\
\hline 83 & 9 & 20 & 10.125 & 73 & 75 & 90 \\
\hline 84 & 40 & 58 & 10.333 & 67 & 54 & 93 \\
\hline 85 & 25 & 45 & 10.444 & 74 & 7 & 94 \\
\hline \hline 86 & 12 & 18 & 10.933 & 76 & 64 & 95 \\
\hline \hline 87 & 1 & 4 & 11.729 & 80 & 81 & 89 \\
\hline \hline 88 & 15 & 35 & 12.000 & 65 & 0 & 91 \\
\hline \hline 89 & 1 & 3 & 13.408 & 87 & 0 & 91 \\
\hline \hline 90 & 9 & 22 & 13.850 & 83 & 82 & 92 \\
\hline 91 & 1 & 15 & 13.916 & 89 & 88 & 95 \\
\hline 92 & 7 & 9 & 14.286 & 58 & 90 & 93 \\
\hline 93 & 7 & 40 & 15.078 & 92 & 84 & 98 \\
\hline \hline 94 & 25 & 88 & 15.091 & 85 & 0 & 96 \\
\hline 95 & 1 & 12 & 15.686 & 91 & 86 & 96 \\
\hline 96 & 1 & 25 & 17.386 & 95 & 94 & 97 \\
\hline
\end{tabular}




\begin{tabular}{|l|r|r|r|r|r|r|}
\hline $\mathbf{9 7}$ & 1 & 2 & $\mathbf{1 7 . 8 1 3}$ & 96 & 0 & 99 \\
\hline $\mathbf{9 8}$ & 7 & 69 & $\mathbf{2 0 . 3 9 1}$ & 93 & 0 & 99 \\
\hline 99 & 1 & 7 & 20.581 & 97 & 98 & 0 \\
\hline
\end{tabular}

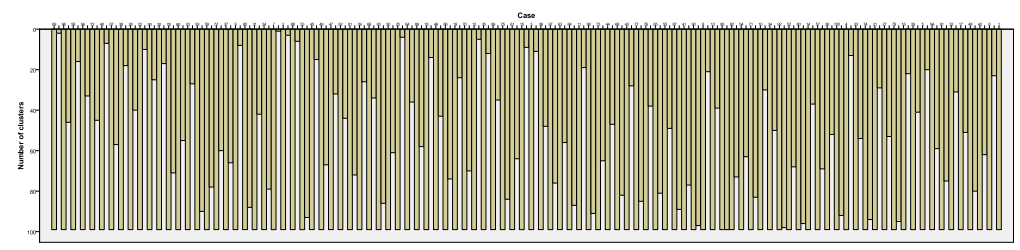

Fig 1: Icicle Table

Table 3: Hierarchical Cluster Analysis

Dendrogram using Average Linkage (Between Groups)

\section{Rescaled Distance Cluster Combine}

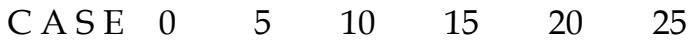
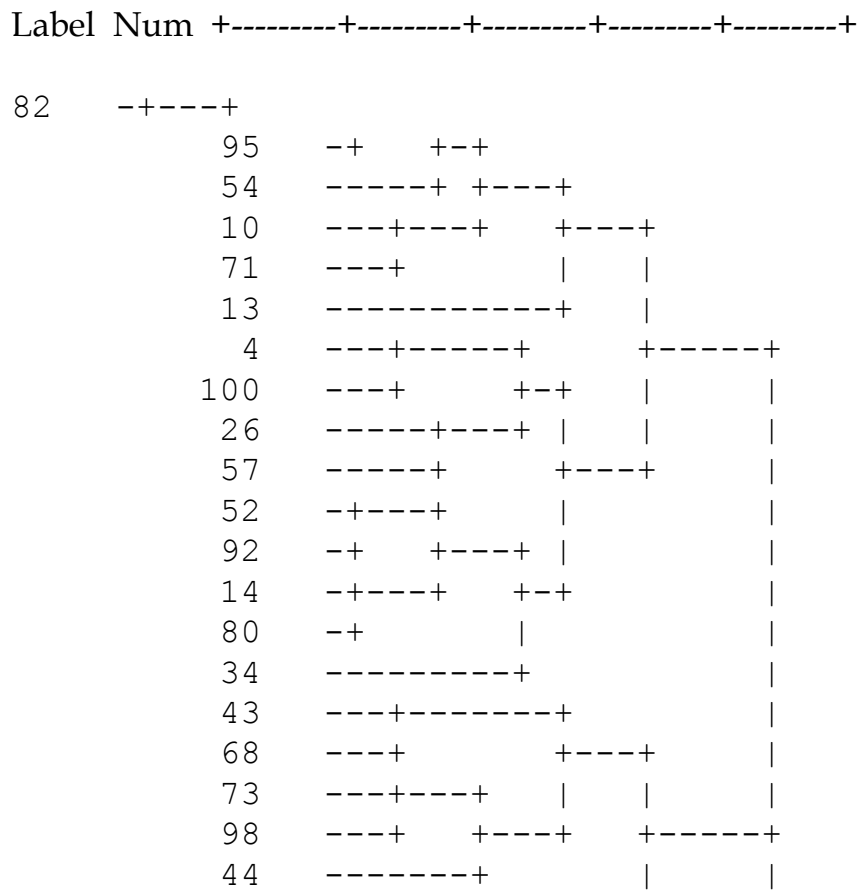


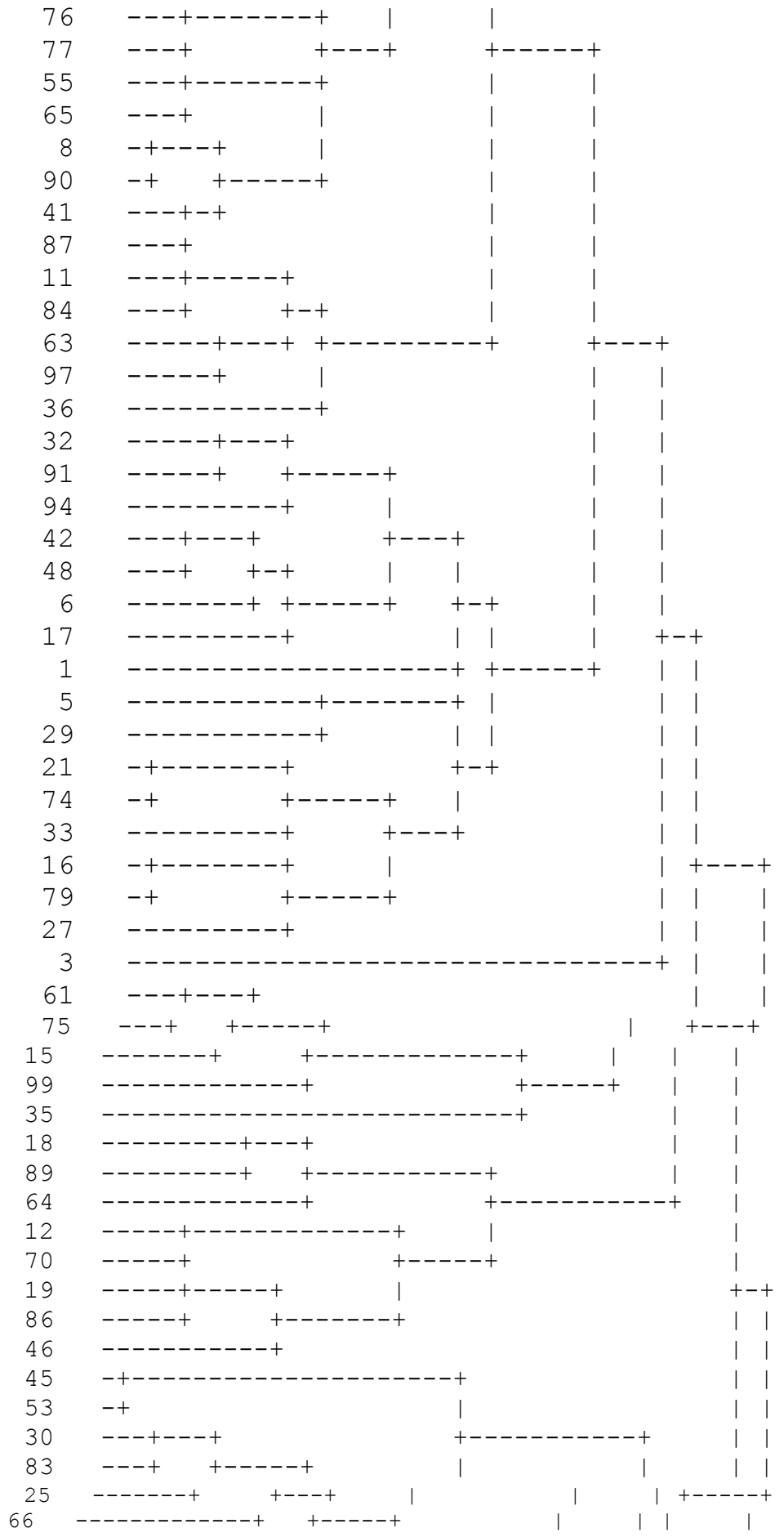


A Study on Identification of Consumer Groups Ushus JBMgt 12, 4 (2013)

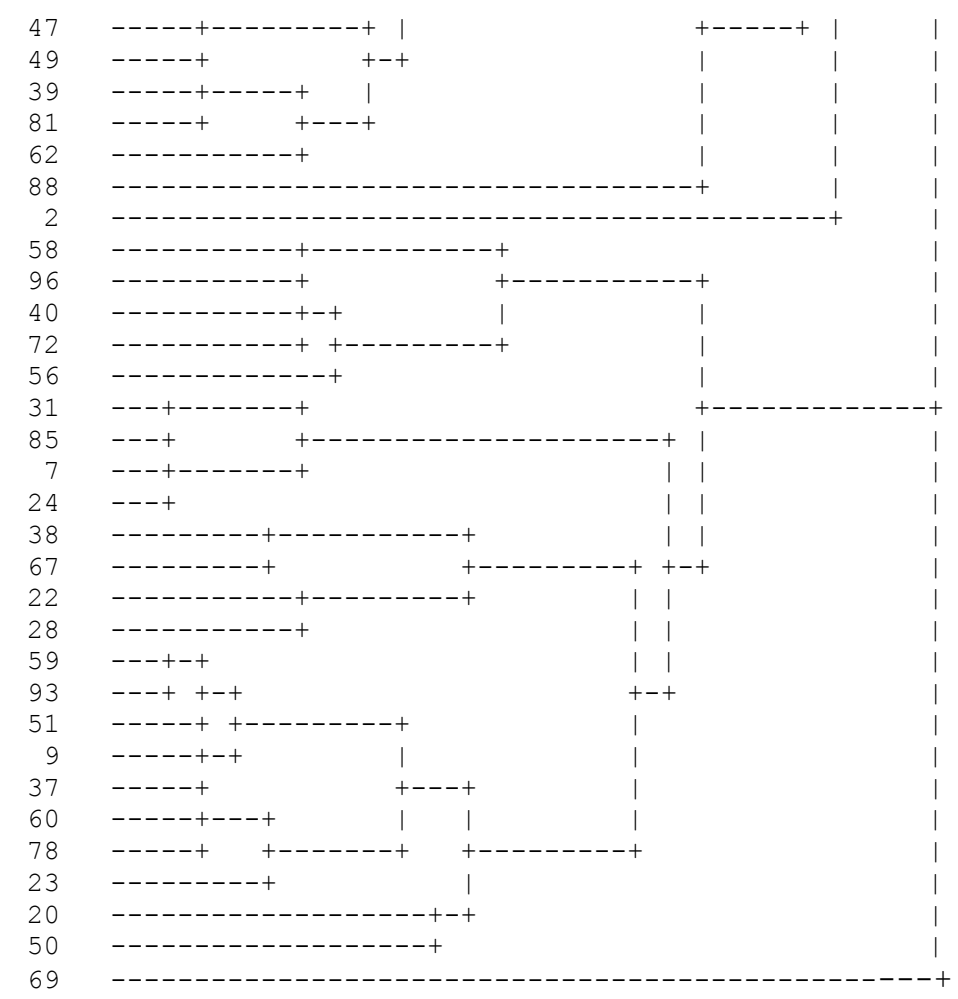

\begin{tabular}{|l|l|c|c|c|}
\hline Table 4: Correlations & Loyalty & Occupation & $\begin{array}{c}\text { Overall } \\
\text { Satisfaction of } \\
\text { the Store }\end{array}$ \\
\hline Loyalty & $\begin{array}{l}\text { Pearson } \\
\text { Correlation }\end{array}$ & 1 & $.311^{* *}$ & \\
\cline { 2 - 5 } & Sig. (2-tailed) & & .002 & \\
\cline { 2 - 5 } & $\mathrm{N}$ & 100 & 100 & \\
\hline Occupation & $\begin{array}{l}\text { Pearson } \\
\text { Correlation }\end{array}$ & $.311^{* *}$ & 1 & $.227^{*}$ \\
\cline { 2 - 5 } & Sig. (2-tailed) & .002 & & .023 \\
\cline { 2 - 5 } & $\mathrm{N}$ & 100 & 100 & 100 \\
\hline **. Correlation is significant at the 0.01 level (2-tailed). & \\
\hline
\end{tabular}




\section{References}

Bearden, W. O., \& Teel, J.E. (1983). Selected determinants of consumer satisfaction and complaint reports. Journal of Marketing Research, 20:2, 21- 28.

Day, R. L., (1984). Modelling choices among alternative responses to dissatisfaction. Advances in Consumer Research, 11, 469-499.

Dekimpe, M.G., Steenkamp, J.B E.M., Mellens, M. and Abeele, P.V. (1997). Decline and variability in brand loyalty. International. Journal of Research in Marketing, 14(5), 405-420.

Lowenstein, M.W. (1995). Customer retention: An integrated process for keeping your best customers. ASQC, Milwaukee, WI.

Oliver, R.L. (1999). Whence consumer loyalty? Journal of Marketing, 63(5), 33-45.

Reichheld, F.F., (1996). The loyalty effect-the hidden force behind growth, profits and lasting value, Boston: Harvard Business School Press Books, 29(6), 909.

Stone, M., Woodcock, N. \& Wilson, M. (1996). Managing the change from marketing planning to customer relationship management. Long Range Planning, 29(5), 675-683. 